\title{
BMJ Open Usage of ambulance transport and influencing factors in acute coronary syndrome: a cross-sectional study at a tertiary centre in China
}

\author{
Jingjing Ma, ${ }_{1,2,3,4}$ Jiali Wang, ${ }^{1,2,3,4}$ Wen Zheng, ${ }^{1,2,3,4}$ Jiaqi Zheng, ${ }^{1,2,3,4}$ \\ Hao Wang, ${ }^{1,2,3,4}$ Guangmei Wang, ${ }^{1,2,3,4}$ He Zhang, ${ }^{1,2,3,4}$ Feng Xu, ${ }^{1,2,3,4}$ \\ Yuguo Chen ${ }^{1,2,3,4}$
}

To cite: Ma J, Wang J, Zheng W, et al. Usage of ambulance transport and influencing factors in acute coronary syndrome: a crosssectional study at a tertiary centre in China. BMJ Open 2017;7:e015809. doi:10.1136/ bmjopen-2016-015809

- Prepublication history and additional material for this paper are available online. To view these files please visit the journal online (http://dx.doi. org/10.1136/bmjopen-2016015809).

Received 5 January 2017 Revised 2 June 2017 Accepted 3 July 2017

\section{CrossMark}

${ }^{1}$ Department of Emergency, Qilu Hospital, Shandong University, Jinan, China

${ }^{2}$ Chest Pain Centre, Qilu Hospital, Shandong University, Jinan, China

${ }^{3}$ Key Laboratory of Emergency and Critical Care Medicine of Shandong Province, Qilu Hospital, Shandong University, Jinan, China

${ }^{4}$ Key Laboratory of Cardiovascular Remodeling \& Function Research, Chinese Ministry of Education \& Chinese Ministry of Public Health, Qilu Hospital, Shandong University, Jinan, China

Correspondence to

Dr Yuguo Chen;

chen919085@sdu.edu.cn

\section{ABSTRACT}

Objectives The aim of this study was to explore the choice of transportation mode to hospital in patients with acute coronary syndrome (ACS) and to determine the factors influencing the use of ambulance.

Design, setting and participants This cross-sectional study was conducted in a tertiary and teaching hospital in China. The study was carried out between 24 August 2015 and 24 July 2016. A total of 828 patients with ACS presented at the emergency department (ED) were included. The study population was dichotomised according to their primary mode of transport (ambulance or self-transport) to hospital. Social demographics, cardiovascular history, risk factors, prehospital medications, clinical characteristics and symptom characteristics were collected. Multivariable logistic regression was used to examine the factors associated with ambulance use.

Results We found that only $179(21.6 \%)$ patients with ACS chose taking ambulance to hospital. Factors associated with ambulance use were single (OR 1.66, $95 \% \mathrm{Cl} 1.07$ to 2.57), taking Suxiaojiuxin pills (OR 1.91, 1.31 to 2.80 ) or nitrates (OR 2.91, 1.70 to 4.99 ) before going to hospital, diagnosed as ST-elevation myocardial infarction (STEMI) (OR 2.43, 1.45 to 4.05), with persistent symptoms (OR 1.95, 1.33 to 2.86) and symptoms accompanied with vomiting (OR 2.35, 1.19 to 4.62). The patients who had symptoms precipitated or aggravated by exercise (OR $0.37,0.14$ to 0.98 ) tended to choose selftransport.

Conclusion The usage of ambulance in patients with ACS presenting to the ED was low in China. Factors like single, taking Suxiaojiuxin pills or nitrates before going to hospital, diagnosed as STEMI, accompanied with vomiting and persistent symptoms were independently associated with ambulance use. Future education programmes should focus on these factors and increase people's knowledge on ACS and the benefits of ambulance use.

\section{INTRODUCTION}

Since 2000, a rapid steady increase in acute coronary syndrome (ACS) prevalence has been observed throughout China, which has
Strengths and limitations of this study

- This study provides the insights into the usage of ambulance transport among patients with acute coronary syndrome (ACS) in China.

- The study used cross-sectional data to investigate influencing factors of ambulance use in patients with ACS.

- This study is confined to only participants from a single centre. Therefore, the findings from this study may not be generalisable to other centres.

- The study did not describe the cost of ambulance use and the distance each patient lives from the hospital, which may likely affected the choice of the patient to some extent.

- With greater study duration or more centres participated in, more patients would be enrolled to strengthen the power of the study.

become a leading cause of mortality. ${ }^{1}$ For patients with ACS, early symptom recognition, early activation of emergency medical service (EMS), early transportation to the hospital and early administration of definitive treatment are associated with improved clinical outcomes. ${ }^{2}$

Guidelines from European Society of Cardiology, ${ }^{3}$ American College of Cardiology (ACC) and American Heart Association $(\mathrm{AHA})^{2}{ }^{4}$ strongly recommend activation of the EMS, a rapid and effective means of obtaining medical care, for patients who have symptoms consistent with ACS. EMS is critical to provide an opportunity for earlier initiation of evidence-based therapies, faster receipt of initial reperfusion therapies and also earlier coordination with capable centres for efficient delivery of care. ${ }^{56}$ In spite of this, several studies found that a significant proportion of patients with ACS failed to use EMS, the percentage of EMS 
use ranged from $4.5 \%$ to $50.4 \%$ in different regions of the world. ${ }^{7-11}$

Although previous attempts such as public education and media campaigns had been taken to increase the consciousness of patients to activate EMS when having a heart attack, limited success was achieved and individuals were still hesitant to contact the EMS as means of transport to the emergency department (ED) ${ }^{12-15}$ In order to increase EMS use, we need to know the influencing factors of EMS use and identify the accurate improving targets. Previous studies have reported that social demographics like old age ${ }^{4516}$ and female sex, ${ }^{5}$ history of heart diseases, ${ }^{5} 1116$ haemodynamic complications ${ }^{4}$ and living far from the hospital ${ }^{411}$ were associated with more ambulance use. Besides, persistent symptoms, ${ }^{11} 17$ lack of physical activity at the time of symptom onset, ${ }^{16}$ abrupt onset of chest pain and associated symptoms such as nausea or cold sweat ${ }^{11} 17$ were also associated with increased usage of EMS. Nevertheless, race, income and education level ${ }^{47}$ did not appear to be associated with the mode of transport to hospital.

To date, no data have been published on ambulance use of patients with ACS in China. Therefore, the objectives of this cross-sectional study were to explore the usage of ambulance transport and to determine factors influencing the use of ambulance among patients with ACS in China.

\section{METHODS}

\section{Study population}

Patients with diagnosis of ACS presenting to the ED of Qilu Hospital of Shandong University were consecutively enrolled from 24 August 2015 to 24 July 2016. Qilu Hospital of Shandong University is an academic medical centre, tertiary and teaching hospital located in urban area in China.

Patients were included if they were (1) 18 years and older, (2) with ACS symptoms occurred within 24 hours, (3) presenting to the ED, (4) diagnosed as ACS and (5) signed an informed consent by themselves or next of kin. Patients transferred from other hospitals or presented to the ED again within 30 days after initial enrolment were excluded.

EMS system has been well established in China, an ambulance is staffed by at least three crews: a doctor, a nurse and a driver. Equipment of advanced life supports and a 12-lead ECG are standard on board. EMS system is available to all patients with ACS who are making the decisions to activate EMS.

Ethical approval was obtained from the ethics committee before initiation of the study and all patients provided informed consent.

\section{Data collection}

Patients with an ACS event were initially screened and then invited by a trained research nurse to participate in the study. According to the standard data collection protocol developed by the steering committee, data collection was conducted on a standardised case report form, in which the variables are in accordance with the international standards. ${ }^{18}$ Data on the social demographics, cardiovascular history, risk factors, prehospital medications and symptom characteristics were obtained through patient interviews and then supplemented and confirmed from the medical records. Data on the clinical characteristics, initial ECG, biochemical markers and final ED diagnosis were based on medical records. Research nursing staff collected all the data.

The criteria used for the diagnosis of ACS are the criteria approved by the ACC/AHA, namely, a clinical syndrome defined by characteristic symptoms suggestive of myocardial ischaemia with or without persistent relevant electrocardiographic changes and/or release of biomarkers of myocardial necrosis. ${ }^{2}$

Self-transport was defined as any mode of transportation that did not involve ambulance, including taking taxis or any public transportation, driving by themselves, driven by others and walking to the hospital.

The symptom characteristics were mainly derived from Hollander et al. ${ }^{19}$ In order to distinguish the primary symptoms leading to ED presentation, chief complaints were classified into chest pain, chest discomfort and pain/ discomfort outside chest. 'Chest pain' included all kinds of pain, such as squeezing, stabbing, sharp and others. 'Chest discomfort' included other symptom episodes in the chest except of pain, while "pain/discomfort outside chest' was defined as pain or discomfort occurring at epigastrium, neck, jaw, shoulder, left arm and others. The maximum intensity of pain was measured by a Numerical Rating Scale where ' 0 ' means no pain and ' 10 ' means unbearable pain.

The final ED diagnosis was defined as the discharge diagnosis for patients discharged home or the admitting diagnosis for patients admitted to an inpatient setting.

\section{Statistical analysis}

The descriptive results are presented as the median (25th, 75th percentile), mean \pm SD for continuous variables and frequency and percentage for categorical variables. Comparison between groups was made by t-test and Wilcoxon rank-sum test for continuous variables appropriately. With regard to categorical variables, $\chi^{2}$ test or Fisher's exact test was used.

Multivariable logistic regression was used to examine factors associated with ambulance use. Four models were built separately to analyse the association between ambulance use and different aspects of characteristics including the social demographics, cardiovascular history and risk factors, prehospital medications and clinical characteristics, and symptom characteristics (see online supplementary file 1$)$. Then, the statistically significant variables $(p \leq 0.05)$ in each model were included into the final multivariable logistic regression model. $p$ Value was reported for whether the logistic model was significant as a whole. Max-rescaled $\mathrm{R}^{220}$ was computed as measures 
Table 1 Social demographics, cardiovascular history and risk factors comparing ambulance-transported patients and selftransported patients with ACS

\begin{tabular}{|c|c|c|c|}
\hline & Ambulance $(n=179)$ & Self-transport $(n=649)$ & p Value \\
\hline \multicolumn{4}{|l|}{ Social demographics } \\
\hline Age, years (SD) & $67 \pm 12$ & $66 \pm 11$ & 0.91 \\
\hline Sex (male), n (\%) & $94(52.5)$ & $334(51.5)$ & 0.8 \\
\hline Marital status & & & $<0.01$ \\
\hline Single (unmarried, divorced, widowed), n (\%) & $45(25.1)$ & $102(15.7)$ & \\
\hline Married, n (\%) & $134(74.9)$ & $547(84.3)$ & \\
\hline Occupation & & & 0.07 \\
\hline Government, private, business, $\mathrm{n}(\%)$ & $35(19.6)$ & $108(16.6)$ & \\
\hline Manual labourer, n (\%) & $15(8.4)$ & $92(14.2)$ & \\
\hline Other, n (\%) & $9(5.0)$ & $17(2.6)$ & \\
\hline Retired, n (\%) & $120(67.0)$ & $432(66.6)$ & \\
\hline Education level & & & 0.6 \\
\hline No education, $\mathrm{n}(\%)$ & $11(6.2)$ & $42(6.5)$ & \\
\hline Primary school, n (\%) & $25(14.0)$ & $107(16.5)$ & \\
\hline Middle school, n (\%) & $38(21.2)$ & $156(24.0)$ & \\
\hline High school, n (\%) & $105(58.7)$ & $344(53.0)$ & \\
\hline Health insurance & & & 0.51 \\
\hline Provincial medical insurance, $\mathrm{n}(\%)$ & $37(20.7)$ & $117(18.0)$ & \\
\hline Urban worker medical insurance, $n(\%)$ & $97(54.2)$ & $348(53.6)$ & \\
\hline Urban residents medical insurance, $\mathrm{n}(\%)$ & $28(15.6)$ & $131(20.2)$ & \\
\hline Other, n (\%) & $17(9.5)$ & $53(8.2)$ & \\
\hline \multicolumn{4}{|l|}{ Cardiovascular history } \\
\hline MI, n (\%) & $58(32.4)$ & $173(26.7)$ & 0.13 \\
\hline $\mathrm{PCl}, \mathrm{n}(\%)$ & $47(26.3)$ & $164(25.3)$ & 0.79 \\
\hline CABG, n (\%) & $8(4.5)$ & $14(2.2)$ & 0.09 \\
\hline Heart failure, n (\%) & $5(2.8)$ & $9(1.4)$ & 0.2 \\
\hline \multicolumn{4}{|l|}{ Risk factors } \\
\hline Current Smoking, n (\%) & $40(22.4)$ & $98(15.1)$ & 0.02 \\
\hline Diabetes mellitus, $\mathrm{n}(\%)$ & $67(37.4)$ & $198(30.5)$ & 0.08 \\
\hline Hypertension, n (\%) & $119(66.5)$ & $432(66.6)$ & 0.98 \\
\hline Hyperlipaemia, n (\%) & $23(12.9)$ & 75 (11.6) & 0.64 \\
\hline Stroke, n (\%) & 35 (19.6) & $97(15.0)$ & 0.14 \\
\hline
\end{tabular}

ACS, acute coronary syndrome; CABG, coronary artery bypass graft; $\mathrm{MI}$, myocardial infarction; PCl, percutaneous coronary intervention.

to assess the goodness of model fit. Factors included in the final multivariable logistic regression model were as follows: marital status, current smoking, prehospital medications (Suxiaojiuxin pills, ${ }^{\mathrm{i}}$ nitrates), time of presentation (day, evening, night), diagnosis (ST-elevation myocardial infarction (STEMI)/non-ST-elevation ACS), associated symptoms (vomiting, sweating), nature of main symptom (persistent), precipitating and aggravating factors (exercise), relieving factors (nitrates). The

\footnotetext{
${ }^{\mathrm{i}}$ A Chinese medicine, which can invigorate the circulation and remove stasis pain so as to increase coronary blood flow and relieve symptoms of angina. Mainly used for coronary heart disease, angina pectoris.
}

results are expressed as the OR and 95\% CI. Analyses were performed with SAS V.9.4 statistical package (SAS Institute). $\mathrm{p} \leq 0.05$ was considered statistically significant.

\section{RESULTS}

A total of 828 patients with ACS participated in the study (51.3\% men). The mean age was $66 \pm 11$ years (men $64 \pm 12$ years, women $69 \pm 10$ years). Only 179 (21.6\%) patients activated ambulance for transport to hospital. Social demographics, cardiovascular history and risk factors of all patients were listed in table 1 . No statistical differences regarding age and gender were found. The 
Table 2 Prehospital medications and clinical characteristics comparing ambulance-transported patients and self-transported patients with ACS

\begin{tabular}{|c|c|c|c|}
\hline & Ambulance $(n=179)$ & Self-transport $(n=649)$ & $p$ value \\
\hline \multicolumn{4}{|l|}{ Prehospital medications } \\
\hline Suxiaojiuxin pills, n (\%) & $108(60.3)$ & $341(52.5)$ & 0.06 \\
\hline Nitrates, n (\%) & $74(41.3)$ & $133(20.5)$ & $<0.01$ \\
\hline Aspirin, $\mathrm{n}(\%)$ & $17(9.5)$ & $26(4.0)$ & $<0.01$ \\
\hline $\mathrm{P} \mathrm{Y}_{12}$ inhibitors, $\mathrm{n}(\%)$ & $2(1.1)$ & $7(1.1)$ & \\
\hline Statins, n (\%) & $1(0.6)$ & $3(0.5)$ & 0.87 \\
\hline \multicolumn{4}{|l|}{ Clinical characteristics } \\
\hline Systolic blood pressure (mm Hg), mean (SD) & $142 \pm 27$ & $150 \pm 26$ & $<0.01$ \\
\hline Diastolic blood pressure ( $\mathrm{mm} \mathrm{Hg}$ ), mean (SD) & $80 \pm 15$ & $83 \pm 17$ & 0.02 \\
\hline Heart rate (beats/min), mean (SD) & $79 \pm 20$ & $79 \pm 17$ & 0.91 \\
\hline Cardiogenic shock on presentation, $\mathrm{n}(\%)$ & $6(3.4)$ & $7(1.1)$ & 0.04 \\
\hline Heart failure on presentation, $\mathrm{n}(\%)$ & $18(10.1)$ & $51(7.9)$ & 0.35 \\
\hline Time of presentation & & & 0.02 \\
\hline Day (8 am-4 pm), n (\%) & $73(40.8)$ & $296(45.6)$ & \\
\hline Evening (4 pm-12 pm), n (\%) & $62(34.6)$ & $251(38.7)$ & \\
\hline Night (12 pm-8 am), n (\%) & $44(24.6)$ & $102(15.7)$ & \\
\hline Diagnosis & & & $<0.01$ \\
\hline STEMI, n (\%) & $44(24.6)$ & $64(9.9)$ & \\
\hline NSTE-ACS, n (\%) & $135(75.4)$ & $585(90.1)$ & \\
\hline
\end{tabular}

ACS, acute coronary syndrome; NSTE-ACS, non-ST-elevation acute coronary syndrome; STEMI, ST-elevation myocardial infarction.

ambulance-transported patients were more likely to be single $(25.1 \%$ vs $15.7 \%, \mathrm{p}<0.01)$ and had current smoking more frequently $(22.4 \%$ vs $15.1 \%$, $\mathrm{p}=0.02)$ compared with the self-transported patients.

Table 2 lists the prehospital medications and clinical characteristics of all patients. When considering actions taken by patients before calling ambulance or going to the hospital, ambulance-transported patients were more likely to take Suxiaojiuxin pills ( $60.3 \%$ vs $52.5 \%, \mathrm{p}=0.06)$, nitrates $(41.3 \%$ vs $20.5 \%, \mathrm{p}<0.01)$ or aspirin $(9.5 \%$ vs $4.0 \%, \mathrm{p}<0.01)$. Compared with self-transported patients, ambulance-transported patients were often with more haemodynamic instability on presentation, like lower systolic blood pressure $(142 \pm 27 \mathrm{~mm} \mathrm{Hg}$ vs $150 \pm 26 \mathrm{~mm} \mathrm{Hg}$, $\mathrm{p}<0.01)$, lower diastolic blood pressure $(80 \pm 15 \mathrm{~mm} \mathrm{Hg}$ vs $83 \pm 17 \mathrm{~mm} \mathrm{Hg}, \mathrm{p}=0.02)$ and a higher incidence of cardiogenic shock (3.4\% vs $1.1 \%, \mathrm{p}=0.04)$. Patients were more likely to choose ambulance when symptom occurred at night $(24.6 \%$ vs $15.7 \%, \mathrm{p}=0.02)$. STEMI was found in $24.6 \%$ of the ambulance-transported group, whereas it was only $9.9 \%$ of the self-transported group $(\mathrm{p}<0.01)$.

Table 3 lists the symptom characteristics comparing ambulance-transported patients and self-transported patients. Chest pain was the most common symptom occurring in $60 \%$ of all patients. There were no statistical differences in chief complaint proportions between the two groups $(\mathrm{p}=0.44)$. The median of maximum intensity of pain was 6 in the ambulance-transported group and 5 in the self-transported group $(\mathrm{p}<0.01)$. Associated symptoms like nausea $(25.7 \%$ vs $18.3 \%, \mathrm{p}=0.03)$, vomiting $(13.4 \%$ vs $4.3 \%, \mathrm{p}<0.01)$ or sweating ( $36.3 \%$ vs $26.7 \%, \mathrm{p}=0.01)$, as well as persistent symptoms ( $57.3 \%$ vs $36.4 \%, \mathrm{p}<0.01)$ and symptoms relieved by nitrates $(22.9 \%$ vs $13.9 \%, \mathrm{p}<0.01)$ were associated with increased use of ambulance, while symptoms precipitated or aggravated by exercise $(2.8 \%$ vs $9.4 \%, \mathrm{p}<0.01)$ or relieved by rest $(6.7 \%$ vs $16.3 \%, \mathrm{p}<0.01)$ were associated with decreased use of ambulance.

The result of final multivariable logistic regression analysis (table 4) showed that single (OR 1.66, 95\% CI 1.07 to 2.57 ), taking Suxiaojiuxin pills (OR 1.91, 1.31 to 2.80 ) or nitrates (OR 2.91, 1.70 to 4.99) before going to hospital, diagnosed as STEMI (OR 2.43, 1.45 to 4.05), accompanied with vomiting (OR 2.35, 1.19 to 4.62 ) and persistent symptoms (OR 1.95, 1.33 to 2.86) were factors independently associated with increased ambulance use. Symptom precipitated or aggravated by exercise (OR $0.37,0.14$ to 0.98 ) was an independent factor associated with less ambulance use. The model was statistically significant $(\mathrm{p}<0.01)$ with moderate max-rescaled $\mathrm{R}^{2}(0.19)$.

\section{DISCUSSION}

The first finding in this study was that only $21.6 \%$ of the patients with ACS were transported to the hospital by ambulance. In 1997 in Tianjin City, Wu $e t a l^{21}$ found that less than $10 \%$ patients reached the hospital via ambulance. Nearly two decades later, there is only a little progress of activating EMS by patients with ACS presenting to ED 
Table 3 Symptom characteristics comparing ambulance-transported patients and self-transported patients with acute coronary syndrome

\begin{tabular}{|c|c|c|c|}
\hline & Ambulance $(n=179)$ & Self-transport $(n=649)$ & p Value \\
\hline Chief complaint & & & 0.44 \\
\hline Chest pain, n (\%) & $113(63.1)$ & $398(61.3)$ & \\
\hline Pain/discomfort outside chest, n (\%) & $18(10.1)$ & $51(7.9)$ & \\
\hline \multicolumn{4}{|l|}{ Chest pain } \\
\hline Stabbing & $14(12.4)$ & $69(17.3)$ & 0.21 \\
\hline Sharp & $2(1.8)$ & $3(0.8)$ & 0.31 \\
\hline Burning & $8(7.1)$ & $30(7.5)$ & 0.87 \\
\hline Pressing & $6(5.3)$ & $16(4.0)$ & 0.6 \\
\hline Swelling & $11(9.7)$ & $43(10.8)$ & 0.74 \\
\hline Angina & $9(8.0)$ & $30(7.5)$ & 0.84 \\
\hline Other & $23(20.4)$ & $85(21.4)$ & 0.82 \\
\hline Maximum intensity of pain (scale $0-10$ ), median & $6(5,8)$ & $5(4,7)$ & $<0.01$ \\
\hline Radiation of pain, n (\%) & $59(52.2)$ & $205(51.5)$ & 0.89 \\
\hline \multicolumn{4}{|l|}{ Associated symptoms, n (\%) } \\
\hline Palpitation & $30(16.8)$ & 80 (12.3) & 0.14 \\
\hline Syncope & $3(1.7)$ & $6(0.9)$ & 0.42 \\
\hline Nausea & $46(25.7)$ & $119(18.3)$ & 0.03 \\
\hline Nature of main symptom, n (\%) & & & $<0.01$ \\
\hline Paroxysmal & $76(42.7)$ & $412(63.6)$ & \\
\hline Persistent & $102(57.3)$ & $236(36.4)$ & \\
\hline \multicolumn{4}{|l|}{ Precipitating and aggravating factors, $\mathrm{n}(\%)$} \\
\hline Deep inspiration/cough & $0(0.0)$ & $2(0.3)$ & 1 \\
\hline Position change & $1(0.6)$ & $4(0.6)$ & 1 \\
\hline Tiredness & $36(20.1)$ & $95(14.6)$ & 0.08 \\
\hline Palpation & $0(0.0)$ & $0(0.0)$ & \\
\hline Exercise & $5(2.8)$ & $61(9.4)$ & $<0.01$ \\
\hline Emotion and stress & $18(10.1)$ & $66(10.2)$ & 0.96 \\
\hline Eating & $3(1.7)$ & $12(1.9)$ & 1 \\
\hline Other & $16(8.9)$ & $39(6.0)$ & 0.16 \\
\hline \multicolumn{4}{|l|}{ Relieving factors, n (\%) } \\
\hline Nitrates & $41(22.9)$ & $90(13.9)$ & $<0.01$ \\
\hline Suxiaojiuxin pills & $52(29.1)$ & $229(35.3)$ & 0.12 \\
\hline Isosorbide dinitrate & $1(0.6)$ & $2(0.3)$ & 0.52 \\
\hline Antacids & $0(0.0)$ & $0(0.0)$ & \\
\hline Rest & $12(6.7)$ & $106(16.3)$ & $<0.01$ \\
\hline
\end{tabular}


Table 4 Independent factors associated with choosing or not choosing ambulance in patients with ACS

\begin{tabular}{|c|c|c|c|}
\hline & OR & $95 \% \mathrm{Cl}$ & p Value \\
\hline \multicolumn{4}{|l|}{ Marital status } \\
\hline Married & Reference & & \\
\hline Single (unmarried, divorced, widowed) & 1.66 & 1.07 to 2.57 & 0.02 \\
\hline \multicolumn{4}{|l|}{ Risk factors } \\
\hline Current smoking & 1.5 & 0.94 to 2.41 & 0.09 \\
\hline \multicolumn{4}{|l|}{ Prehospital medications (yes/no) } \\
\hline Suxiaojiuxin pills & 1.91 & 1.31 to 2.80 & $<0.01$ \\
\hline Nitrates & 2.91 & 1.70 to 4.99 & $<0.01$ \\
\hline \multicolumn{4}{|l|}{ Time of presentation } \\
\hline Day (8 am-4 pm) & Reference & & \\
\hline Evening (4 pm-12 pm) & 1.01 & 0.67 to 1.52 & 0.28 \\
\hline Night (12 pm-8 am) & 1.56 & 0.97 to 2.52 & 0.05 \\
\hline \multicolumn{4}{|l|}{ Diagnosis } \\
\hline NSTE-ACS & Reference & & \\
\hline STEMI & 2.43 & 1.45 to 4.05 & $<0.01$ \\
\hline \multicolumn{4}{|l|}{ Associated symptoms (yes/no) } \\
\hline Vomiting & 2.35 & 1.19 to 4.62 & 0.01 \\
\hline Sweating & 1.36 & 0.92 to 2.01 & 0.12 \\
\hline \multicolumn{4}{|l|}{ Nature of main symptom (yes/no) } \\
\hline Persistent & 1.95 & 1.33 to 2.86 & $<0.01$ \\
\hline \multicolumn{4}{|l|}{ Precipitating and aggravating factors (yes/no) } \\
\hline Exercise & 0.37 & 0.14 to 0.98 & 0.05 \\
\hline \multicolumn{4}{|l|}{ Relieving factors (yes/no) } \\
\hline Nitrates & 1.05 & 0.55 to 2.00 & 0.88 \\
\hline
\end{tabular}

Max-rescaled $\mathrm{R}^{2}=0.19, \mathrm{p}<0.01$.

ACS, acute coronary syndrome; NSTE-ACS, non-ST-elevation acute coronary syndrome; STEMI, ST-elevation myocardial infarction.

in China. The situation of EMS use around the world is not optimistic either. Ambulance use rate was reported as $39.8 \%$ and $17 \%$ among hospitalised patients with ACS from Ireland ${ }^{8}$ and the Arab Gulf States ${ }^{9}$ separately, $50.4 \%$ among patients with ACS admitted to intensive cardiac care unit from Sweden ${ }^{11}$ and $23 \%$ among patients with chest pain from the USA. ${ }^{10}$ In accordance with previous studies, ${ }^{1011}$ we did not find the relationship of gender or age with ambulance use either. Interestingly, we found that ambulance-transported patients were more likely to be single, maybe people who lived by oneself have fewer transportation options but to call ambulance..$^{10}$ Although there was no statistical significance, we found as previous studies reported, ${ }^{451122}$ patients who called ambulance were more likely to have prior major cardiovascular events such as myocardial infarction and heart failure. What's more, patients taking Suxiaojiuxin pills or nitrates before going to the hospital were independent factors associated with increased ambulance use. Brown $e t$ al also found that patients taking nitroglycerin were more likely to use EMS. These patients were more likely to believe that their condition was heart related. ${ }^{10}$ So it suggested that patients with familiar symptoms or experience with a heart attack may have a higher confidence in the current symptoms representing a true event, which encouraged more EMS use as a valued form of medical care and transport. However, the true reasons why these people tended to use ambulance were still unknown. Maybe it is because of after-care teaching at the time of the prior events, which encouraged EMS use. Future research efforts could focus on this area.

Typical ACS symptoms are the trigger for patients to seek medical help. It has previously been shown that patients will call ambulance if they feel their symptoms are serious enough. ${ }^{111617}$ Patients whose symptoms were sudden, severe and persistent were more likely to use ambulance than those whose symptoms were gradual and intermittent, ${ }^{11} 17^{23-25}$ which was supported in our study. Besides, we found that symptom accompanied with vomiting was associated with increased ambulance use, as was STEMI. These results indicated that the more severe symptoms patients experienced, the more frequently they would choose to initiate care by using ambulance. However, a significant factor associated with not choosing ambulance was symptom precipitated or aggravated by exercise. The association between exercise and angina 
or acute myocardial infarction has been well established in the literature. ${ }^{26}$ But why patients with symptoms indicating acute heart ischaemia disease chose to present to the ED by themselves rather than calling ambulance? Several studies have tried to find the possible reasons. First, many non-callers claimed that they did not think their symptoms were severe enough to call an ambulance or they thought self-transport might be faster. ${ }^{11} 121727$ Thuresson et $a l^{11}$ have shown that $46 \%$ of the patients thought "My way was quicker", this was probably true if the patient lived close to a hospital. However, even if self-transport to the hospital was faster, more rapid care was obtained when an ambulance was used. ${ }^{52}$ Second, fear of false alarm, reluctance to bother or burden the medical community and other psychosocial factors such as lack of trust in others have been indicated to be related to less ambulance use. ${ }^{29} 30$ Third, many patients lacked the knowledge about the benefits of activating EMS, and even worse, some patients claimed that they did not even know how to call for an ambulance. ${ }^{731}$

The decision to call an ambulance without delay in response to coronary symptoms needs to become as automatic as calling an ambulance in case of a traffic accident. However, although previous attempts involving public education and media campaigns had been taken to increase the use of the EMS, limited success had been achieved. ${ }^{12-15}$ Explanations were that the campaign periods were too short or only very brief information was given during a limited time. So more detailed public education, especially a continuous long-term message, might be an important way of increasing the use of ambulance in patients with ACS . Besides, information about ACS typical symptoms and atypical symptoms needs to be included in patient education. Moreover, people need to be aware that the ambulance is an extended part of hospital care, with the facilities to start the treatment of ACS.

\section{Limitations}

There are several limitations inherent to this study. First, the principal limitation is that it is a cross-sectional study, which may lead to concerns of residual confounding or bias. Second, since this is a single-centre study, the findings may not be generalisable to other centres. In addition, we did not collect data on the cost of ambulance use and the distance each patient lived from hospital. However, these limitations do not compromise our observation that ambulance use among patients with ACS is still quite underused in China.

\section{CONCLUSIONS}

In summary, there is still ambulance underusage among patients with ACS in China, with only $21.6 \%$ of patients with ACS activated ambulance for transport to hospital when they had a heart attack. Single, taking Suxiaojiuxin pills or nitrates before going to hospital, diagnosed as STEMI, accompanied with vomiting and persistent symptoms were influencing factors associated with more ambulance use, while symptom precipitated or aggravated by exercise was associated with less ambulance use. The results in the present study should be considered when planning educational and information programmes to increase ambulance use in patients with ACS. Future education programmes should focus on increasing the individual's knowledge of ACS symptoms and the benefits of ambulance use, and healthcare professionals may need to be aware of the opportunity to inform patients the severity of heart disease.

Contributors YC, JM and JW conceived the study, designed the trial and obtained research funding. YC, FX, WZ and JM supervised the conduct of the study and data collection. JM, JZ, GW and $\mathrm{HZ}$ undertook recruitment of participating patients and managed the data, including quality control. HW provided statistical advice on study design and analysed the data; WZ chaired the data oversight committee. JM drafted the manuscript and all authors contributed substantially to its revision. YC takes responsibility for the paper as a whole.

Funding This study was supported by Taishan Scholar Program of Shandong Province (ts20130911), Taishan Young Scholar Program of Shandong Province, Key Technology Research and Development Program of Science and Technology of Shandong Province (2014kjhm0102), Department of Science and Technology of Shandong Province (2014GSF11811, 2016GSF201235, 2016ZDJS07A14), Evaluation and Management of Patients with Acute Chest Pain in China (EMPACT) (201525)

Competing interests None declared.

Patient consent Obtained.

Provenance and peer review Not commissioned; externally peer reviewed. Data sharing statement № additional unpublished data are available.

Open Access This is an Open Access article distributed in accordance with the Creative Commons Attribution Non Commercial (CC BY-NC 4.0) license, which permits others to distribute, remix, adapt, build upon this work non-commercially, and license their derivative works on different terms, provided the original work is properly cited and the use is non-commercial. See: http://creativecommons.org/ licenses/by-nc/4.0/

(c) Article author(s) (or their employer(s) unless otherwise stated in the text of the article) 2017. All rights reserved. No commercial use is permitted unless otherwise expressly granted.

\section{REFERENCES}

1. Report on Cardiovascular Diseases in China (2015). National Center for Cardiovascular Diseases, China. Copyright by Encyclopedia of China Publishing House, Beijing, China, 2016.1 ISBN 978-7-50009803-4.

2. O'Gara PT, Kushner FG, Ascheim DD, et al. 2013 ACCF/AHA guideline for the management of ST-elevation myocardial infarction: a report of the American College of Cardiology Foundation/American Heart Association Task Force on Practice Guidelines. Circulation 2013:127:529-55.

3. Van de Werf F, Ardissino D, Betriu A, et al. Management of acute myocardial infarction in patients presenting with ST-segment elevation. The Task Force on the Management of Acute Myocardial Infarction of the European Society of Cardiology. Eur Heart $J$ 2003;24:28-66.

4. Mathews R, Peterson ED, Li S, et al. Use of emergency medical service transport among patients with ST-segment-elevation myocardial infarction: findings from the National Cardiovascular Data Registry Acute Coronary Treatment Intervention Outcomes Network Registry-Get With The Guidelines. Circulation 2011;124:154-63.

5. Canto JG, Zalenski RJ, Ornato JP, et al. Use of emergency medical services in acute myocardial infarction and subsequent quality of care: observations from the National Registry of Myocardial Infarction 2. Circulation 2002;106:3018-23.

6. Cummins RO, Ornato JP, Thies WH, et al. Improving survival from sudden cardiac arrest: the 'chain of survival' concept. A statement for health professionals from the Advanced Cardiac Life Support 
Subcommittee and the Emergency Cardiac Care Committee, American Heart Association. Circulation 1991;83:1832-47.

7. Chew KS, Wan Masliza WM, Nik Hisamuddin NA, et al. A survey on the choice of transportation to come to emergency department among patients with acute coronary syndrome of a community in Malaysia. Med J Malaysia 2015;70:6-11.

8. McKee G, Mooney M, O'Donnell S, et al. Multivariate analysis of predictors of pre-hospital delay in acute coronary syndrome. Int $J$ Cardiol 2013;168:2706-13.

9. Fares S, Zubaid M, Al-Mahmeed W, et al. Utilization of emergency medical services by patients with acute coronary syndromes in the Arab Gulf States. J Emerg Med 2011;41:310-6.

10. Brown AL, Mann NC, Daya M, et al. Demographic, belief, and situational factors influencing the decision to utilize emergency medical services among chest pain patients. Circulation 2000;102:173-8.

11. Thuresson M, Jarlöv MB, Lindahl B, et al. Factors that influence the use of ambulance in acute coronary syndrome. Am Heart $J$ 2008;156:170-6.

12. Eppler E, Eisenberg MS, Schaeffer S, et al. 911 and emergency department use for chest pain: results of a media campaign. Ann Emerg Med 1994;24:202-8.

13. Herlitz J, Blohm M, Hartford M, et al. Follow-up of a 1-year media campaign on delay times and ambulance use in suspected acute myocardial infarction. Eur Heart J 1992;13:171-7.

14. Dracup K, McKinley S, Riegel B, et al. A randomized clinical trial to reduce patient prehospital delay to treatment in acute coronary syndrome. Circ Cardiovasc Qual Outcomes 2009;2:524-32.

15. McGinn AP, Rosamond WD, Goff DC, et al. Trends in prehospital delay time and use of emergency medical services for acute myocardial infarction: experience in 4 US communities from 19872000. Am Heart J 2005;150:392-400.

16. Meischke H, Eisenberg MS, Schaeffer SM, et al. Utilization of emergency medical services for symptoms of acute myocardial infarction. Heart Lung 1995;24:11-18.

17. Johansson I, Strömberg A, Swahn E. Ambulance use in patients with acute myocardial infarction. J Cardiovasc Nurs 2004;19:5-12.

18. Cannon CP, Brindis RG, Chaitman BR, et al. ACCF/AHA key data elements and definitions for measuring the clinical management and outcomes of patients with acute coronary syndromes and coronary artery disease: a report of the American College of Cardiology
Foundation/American Heart Association Task Force on Clinical Data Standards. Circulation 2013;2013:1052-89.

19. Hollander JE, Blomkalns AL, Brogan GX, et al. Standardized reporting guidelines for studies evaluating risk stratification of emergency department patients with potential acute coronary syndromes. Ann Emerg Med 2004;44:589-98.

20. Nagelkerke NJD. A note on a general definition of the coefficient of determination. Biometrika 1991;78:691-2.

21. Wu XD, Wang Y, Zhang F, et al. Analysis of factors associated with prehospital delay in treatment for patients with acute myocardial infarction. Zhongguo Wei Zhong Bing Ji Jiu Yi Xue 1998;10:55-6.

22. Herlitz J, Karlson BW, Bång A, et al. Characteristics and outcome for patients with acute chest pain in relation to whether or not they were transported by ambulance. Eur J Emerg Med 2000;7:195-200.

23. Mooney M, O'Brien F, McKee G, et al. Ambulance use in acute coronary syndrome in Ireland: a cross-sectional study. Eur $J$ Cardiovasc Nurs 2016;15:345-54.

24. O'Donnell S, Moser DK. Slow-onset myocardial infarction and its influence on help-seeking behaviors. J Cardiovasc Nurs 2012;27:334-44.

25. Meischke H, Ho MT, Eisenberg MS, et al. Reasons patients with chest pain delay or do not call 911. Ann Emerg Med 1995;25:193-7.

26. Swap CJ, Nagurney JT. Value and limitations of chest pain history in the evaluation of patients with suspected acute coronary syndromes. JAMA 2005;294:2623-9.

27. Leslie WS, Urie A, Hooper J, et al. Delay in calling for help during myocardial infarction: reasons for the delay and subsequent pattern of accessing care. Heart 2000;84:137-41.

28. Hutchings CB, Mann NC, Daya M, et al. Patients with chest pain calling 9-1-1 or self-transporting to reach definitive care: which mode is quicker? Am Heart $J$ 2004;147:35-41.

29. Mensah GA, Hand MM, Antman EM, et al. Development of systems of care for ST-elevation myocardial infarction patients: the patient and public perspective. Circulation 2007;116:e33-8.

30. Sullivan MD, Ciechanowski PS, Russo JE, et al. Understanding why patients delay seeking care for acute coronary syndromes. Circ Cardiovasc Qual Outcomes 2009;2:148-54.

31. Kopec G, Sobien B, Podolec M, et al. Knowledge of a patientdependant phase of acute myocardial infarction in polish adults: the role of physician's advice. Eur J Public Health 2011;21:603-8. 